\title{
NATIONAL MILITARY COMMAND CENTER - FROM IDEA TO IMPLEMENTATION
}

\author{
Nikolay PETROV
}

\section{Introduction}

The idea for National Military Command Center (NMCC) was derived in the course of $\mathrm{C} 4$ system studies, conducted in several Central and Eastern European countries by US Air Force Electronic System Center, Hanscom AFB, and MITRE Corporation.

A common thread emerged from the analysis of national $\mathrm{C} 4$ system requirements and on-going modernization plans. Basically, all nations, involved in the studies had the same problem. They were engaged in planning for the introduction of centralized information collection and processing systems to support the management of military forces in crisis situations. Because these systems were being planned independently, there was little commonality of system concepts or system architectures. Consequently, the ability to share information among nations in a regional crisis and to collaborate in crisis relief actions would, most likely, be severely limited.

In response to the apparent need for a centralized crisis management capability and in the spirit of the Regional Airspace Initiative, which resulted in an Air Sovereignty Operations Center (ASOC) program, the U.S. Air Force Electronic Systems Center (ESC) developed a concept for implementation of a National Military Command Center for crisis management. This command center, identified as the NMCC, would support both national civil and military crisis situations and, because different national systems would be built on a common architectural platform, it would also support regional collaboration in response to regional crisis situations. This NMCC concept was presented to several nations in the spring of 1999 and met with favorable response.

Based on this response, the U.S. government formally introduced the new policy initiative to Partnership for Peace nations at a multinational conference in Sofia, Bulgaria in June 1999. As described in the U.S. keynote address at the conference, 
the NMCC was intended to provide national command authorities with a modern, integrated command and control facility to support decision-making in the event of civil or military crises. Further, the NMCC will be built on a NATO and UScompatible technical architecture and operational environment platform - NACSP (NATO Common Standard Profile), JTA (Joint Technical Architecture), COE (Common Operating Environment) - and will provide interfaces that are compatible with comparable NATO and U.S. command and control systems. ${ }^{1}$

At the conference seven countries indicated they would collaborate in the initiative, most as active participants. Since that time, several other countries have expressed interest in the initiative. The next step in the process of advancing the initiative was forming a multinational Working Group of potential program participants. The Work group had three meetings - in Predeal, Romania in September 1999, Piestany, Slovakia in March 2000 and Wroclaw, Poland in June 2000. Representatives of the Bulgarian Ministry of Defense (MoD) attended all meetings and presented the national point of view. The Working Group agreed and established a Concept of Operation (CONOPS) and Technical architecture framework for the NMCC. These two documents will serve as the foundation for an acquisition effort for all nations, choosing to participate in the NMCC project.

\section{Vision}

The NMCC is a secure, data integration, information processing, display and distribution command and control facility. It is intended to be used at the MoD General Staff level to support senior national decision-makers in coordinating crisis management activities. The system will interface with national military Service Headquarters, with national military and civil information sources and with national civilian agencies and organizations involved with crisis management. As such, the NMCC is one part of the entire national crisis response mechanism. It may also be used to support regional coordination in the event of crisis situations that affect large regional areas. NMCC functional capabilities will include a core set of features common to all nations, thus promoting interoperability, and an optional set of additional functions tailored to unique operational requirements of the armed forces of each country.

General tasks for the NMCC are:

- To collect and correlate information on the scope and nature of a crisis. This includes situational information, status of forces and resource information.

- To provide means to consolidate information received from disparate sources into a comprehensive picture for decision support at the highest national level. 
- To provide capability to coordinate crisis response activities with other national organizations involved in the crisis management process.

- To provide vehicle for collaboration with regional/coalition partners in cases where crises cross, or may cross national boundaries.

- To provide mechanism for communications and order dissemination to relief units.

The NMCC system hardware and software will comprise mainly commercial off-theshelf (COTS) packages, augmented by government (GOTS) and coalition packages developed to support command and control applications.

\section{Mission}

A crisis can be defined as an incident or situation involving a threat to a country, its territories, citizens, military forces, possessions, or vital interests that develops rapidly and creates a condition of such diplomatic, economic, political, or military importance that commitment of national military forces and resources is contemplated to achieve national objectives. It may occur at a local, provincial/county, national, or regional (international) level. A crisis may be natural or man-made. Examples of crises include: natural disasters (e.g., fires, floods, earthquakes, avalanches), terrorist activity, industrial accidents (e.g., nuclear reactor incident, hazardous material spill), pandemics, aggressive military acts of another country, mass immigration emergencies, civil unrest with acts of violence, and others. ${ }^{2}$

Republic of Bulgaria has laws and plans in place that define what can be done in times of crisis. Most disasters and emergencies are handled by the Civil Protection service, police, fire departments, emergency service, hospitals, and support agencies. The government is asked to provide additional assistance when the consequences of the crisis exceed the local and provincial/county capabilities. Various emergency teams, support personnel, specialized equipment, operating facilities, assistance programs, and access to private sector resources constitute the overall national crisis operations system. Types of assistance needed for crisis management include transportation, communications, public works and engineering, fire fighting, information and planning, resource support, health and medical services, search and rescue, hazardous materials handling, food, and energy. Organizations and agencies involved in the crisis operations include the government; ministries associated with transportation, agriculture, internal affairs, external affairs, defense, justice, etc.; Civil Protection Service; international relief organizations such as the Red Cross or coalition organizations such as the Euro-Atlantic Disaster Response Coordination Centre (EADRCC) of NATO; relief organizations and governments of other 
countries; private sector relief support; and others. ${ }^{3}$ Crisis response actions are usually prioritized as follows:

1. First priority is always the safety of the emergency responders and the public.

2. Second priority is to provide stabilization of the crisis by minimizing the effect that the crisis may have on the surrounding area and maximizing the response effort while using resources efficiently.

3. Third priority is to minimize damage to property while achieving the crisis management objectives.

In addition to crises that affect national interests, Bulgaria also supports peacekeeping operations beyond national borders. Sometimes this may be within the region but sometimes an operation may be further away. Such support may consist of sending humanitarian aid, medical units, engineering units, transportation units, observers, etc. This support requires coordination not only among national agencies, but also international coordination.

\section{Strategy}

The NMCC will be a centralized facility to provide national-level coordinated management for military and civil crisis response. It will be controlled and operated by the General Staff, with civil agency participation/liaisons when necessary.

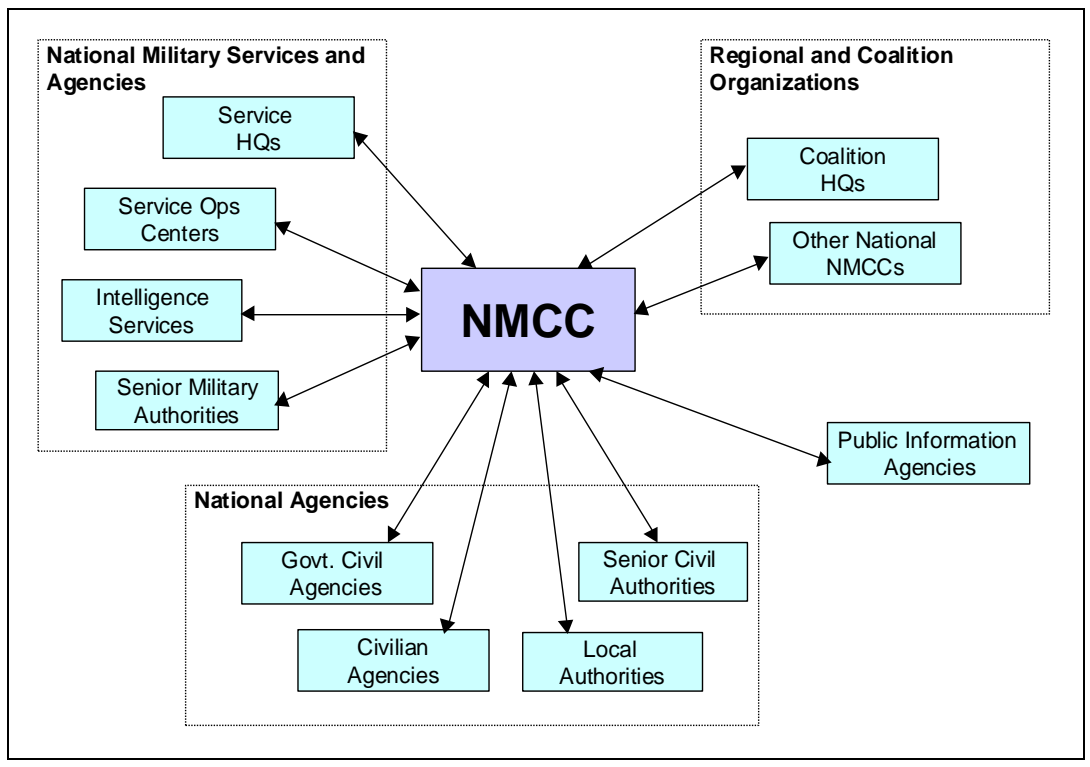

Figure 1. NMCC Operational Relationships 
The NMCC uses interfaces with service headquarters, national military information sources, national civilian agencies/organizations, and regional or foreign agencies/organizations to receive and disseminate information.

The NMCC will be employed at the strategic level within the Bulgarian Armed Forces command and control structure. ${ }^{4}$ It will operate on a 24-hour/7-day schedule. Normal staffing (pre-crisis) is minimal. In times of crisis, a Crisis Action Team (CAT) area will be set up and the staffing for the entire NMCC will be augmented as needed.

In support of crisis management activities, the primary functional capabilities of the NMCC are as follows ${ }^{5}$ :

- Situation Monitoring (information collection/retrieving)

Collection and correlation of information from military services, intelligence sources, civil sources, commercial news services, etc.

- $\quad$ Situation Assessment (information processing)

Evaluation of Force capabilities, planning for resource application, use of mapping displays, access to national emergency planning information, etc.

- Information Distribution

Preparation and distribution of messages to organizations concerned with crisis management.

- Report Generation

Preparation of reports and briefings for senior national authorities and also for use in regional cooperative activities, as well as for coalition authorities (if appropriate).

- Database Management

Generation of and updating databases that are important to crisis management activities. Examples include databases for Logistics, National Infrastructure, Personnel and Medical.

Information will be received, processed, distributed and protected generally by following services ${ }^{6}$ :

- Clear and secure voice;

- $\quad$ Clear and secure email ( SMTP/POP 3, X.400);

- Clear and secure fax;

- Clear and secure messaging - unformatted and formatted (USMTF, ADatP3); 
- $\quad$ Data link (Link 1, Asterix);

- Clear and secure internet/intranet (TCP/IP based LAN/WANs);

- $\quad$ Audio/visual source (e.g., radio, television, VTC - H.320 or IP-based);

- Common Operational Picture/Geographic Information System (COP/GIS) functions

- Computer Aided exercises/Modeling and Simulations (CAX/M\&S) functions;

- Computer Based Training (CBT) / Online Training / Online Help functions;

- Data Management services;

- $\quad$ Firewall equipment and services;

- Guard equipment and services;

- Communications Security (COMSEC) equipment and services;

- $\quad$ Selected gateways;

- $\quad$ Anti-virus software;

- $\quad$ National standards and policy based security key management;

- $\quad$ Printed materials, etc.

In addition, the system may have remote monitors or alarm systems located in the NMCC for disseminating radiation and seismic information.

Through the use of a messaging system and a data link translator, the NMCC will have the capability to automatically process some of the digital data and store it in databases for analysis and presentation. Other information will require operator input or intervention (e.g., manual entry, cutting and pasting, file saving using office automation, database and email capabilities) for adding to the NMCC databases to be displayed later in a graphical or text format.

Operations within the NMCC can be separated into four periods, associated with crisis management: pre-crisis, situation development, crisis response and recovery, and post-crisis. ${ }^{7}$

Pre-crisis operations

Pre-crisis operations are performed when no crisis or potential crisis has been identified. Staffing is minimal and normally occupies the Operations Center. This is often called the "watch-keeping" effort and the NMCC is often called at this point a "Situation Center". 
During pre-crisis operations the following functions are performed:

- Situation monitoring: The NMCC staff will maintain up-to-date situation information using mainly public information sources (e.g., news and weather) and military and national agency sources. This information will include items such as:

- current and predicted weather;

- current events in-country and within the region, e.g., political, social and/or economic activities/ problems/ trends;

- planned activities and resource status reports/updates from the Services and other military or civilian agencies and organizations;

- updates for national and international level shared data such as resource information (equipment, personnel, etc.), joint contingency plans (e.g., plans involving more than one agency, organization, or nation) $;^{8}$

- updates to relevant reference information (e.g., national plans and policies; mapping data such as updated political boundaries, areas of responsibilities, flood plain information, evacuation routes, communications and transportation infrastructures, population densities, fixed support facilities such as potential shelters, hospitals, police/firefighting units, etc.);

- Intelligence information.

- Situation assessment: The NMCC staff will assess the available information to determine the possibility of potential crises. They will use the NMCC's Geographical Information System (GIS) capabilities to view a consolidated situational display Common Operational Picture that fuses situational data from air, land and naval forces) with associated mapping information. The NMCC staff will use links from the Common Operational Picture, as well as database queries and generated reports to analyze database information such as resource status and availability.

- Status reporting: The NMCC staff will provide daily status reports to Service headquarters and national agencies. This will be done using NMCC graphical and textual report generation capabilities and transmitted via voice or data communications, printed format, or formal briefing. Video teleconferencing (VTC) will be used to disseminate this information to selected facilities.

In addition to the above daily functions, the NMCC may support the following:

- Operator training: Workstations for augmentation personnel may be used for operational training purposes during pre-crisis operations. 
- Exercises: The NMCC may be asked to participate in national or regional/coalition exercises. The NMCC would then be required to handle both real and exercise information.

\section{Situation development operations}

Situation development operations are performed when the potential for a crisis or an actual crisis has been identified. The minimal staffing is augmented as the situation escalates. The following functions are performed:

- Situation monitoring: The NMCC staff will continue to maintain up-to-date situation information using military, national, and public information sources. As a situation develops, the NMCC staff will focus on gathering timely detailed information pertinent to the situation. This information will include items such as:

- current and predicted weather (e.g., flood warnings or heavy rains in low-lying areas);

- current events in-country and within the region;

- planned activities, resource status reports/updates, and alerts and warnings;

- from the Services and other military or civilian agencies and organizations;

- updates for shared data such as resource information and joint contingency plans;

- updates to relevant reference information;

- intelligence information;

- Situation assessment: NMCC staff will assess the situation information to determine the nature and possibility of potential crises using the following tools:

- $\quad$ GIS tools, supporting the Common Operation Picture (COP).

- Links from the COP and database tools (e.g., queries, reports). The NMCC staff will identify major constraints (e.g., severe weather, potential breakdown of communications, power or transportation infrastructure, political consequences, etc.).

- Office automation tools will be used to access NMCC plans and procedures that the NMCC staff will follow as the situation escalates, as well as existing contingency plans and Courses of Action (COAs) that may be used in managing the crisis. 
- Coordination: As the situation develops, the NMCC staff will begin coordinating with the Service Headquarters and other national agencies and organizations to request, gather and share information. The NMCC staff will start to coordinate with other nations in the region if the situation could impact areas beyond national borders. Data sharing will include mapping information, resource status, operational plans, etc., using the mechanisms identified in the situation-monitoring paragraph above. Video Teleconferences (VTCs) will be used for the real-time exchange of information with selected facilities. Collaborative tools will also be used for the real-time sharing and modification of information and documentation.

- Notification: NMCC staff will notify senior authorities of a potential or existing crisis normally via voice communications. Senior leadership will officially declare the crisis.

- Status reporting: NMCC staff will provide status reports to Service headquarters and national agencies. This will be done using NMCC graphical and textual report generation capabilities. The reports can be transmitted via voice or data communications, printed format, or formal briefing. VTCs will be used for selected facilities.

\section{Crisis operations}

Crisis operations are performed once a crisis has been officially declared and until $\mathrm{MoD}$ support to the specific crisis has ended. The first step in this period is the creation of a Crisis Action Team(s) - CAT in response to the official crisis declaration and the NMCC staffing is augmented accordingly. Augmentation staff from the previous period (Situation Development) will support the Operations Center or the CAT. All rooms in the NMCC are used. The following functions are performed in the NMCC during crisis operations:

- Crisis monitoring: The NMCC staff will continue to maintain up-to-date situation information using all sources available. Information will be focused on results of field activities.

- Crisis assessment: NMCC staff will continue to assess the situation information to determine the nature and scope of the crisis using the following tools:

- $\quad$ GIS tools, supporting the Common Operation Picture (COP), will be used to display a consolidated recognized situational picture.

- Links from the COP and database tools will be used to access and correlate stored information. Some of this information will be stored 
locally; the NMCC will also have access to other national emergency information managed by other agencies. Using resource status information, NMCC staff will evaluate the nation's continuing capability to respond to the crisis, e.g., what resources (land, maritime, air forces; civilian resources) are needed to respond to the crisis, are they located where they can respond or must they be moved, do they have the resources operational and available to support the crisis, etc.). The NMCC staff will identify major constraints, e.g., severe weather, potential breakdown of communications, power or transportation infrastructure, political consequences, etc.

- Planning: NMCC staff will establish command relationships with the service HQs, based on the nature of the crisis (e.g., a crisis on the Black Sea will require Navy involvement). They will use office automation tools to access NMCC plans and procedures that the NMCC staff will follow as the situation escalates, as well as existing contingency plans and COAs that may be used in managing the crisis. They will review the existing plans and COAs for applicability and recommend additions or modifications to the MoD/General Staff.

- Execution: The NMCC staff will disseminate operational decisions taken by the MoD/General Staff and then monitor the execution of the decisions and the resulting deployment and employment of forces. Through coordination with the various agencies and organizations, the NMCC will identify conflicts or issues and will recommend COAs to the MoD/General Staff for their resolution.

- Coordination: As the crisis evolves, the NMCC staff will continue to coordinate with the Service HQs and other national agencies and organizations to request, gather and share information. The NMCC staff coordinates with other nations in the region, or area of interest, if the situation impacts areas beyond national borders (e.g., flooding, nuclear incidents, peacekeeping activities). Data sharing will include mapping information, resource status, operational plans and status, potential conflicts with resource management/logistics, etc., using the mechanisms identified in the crisis-monitoring paragraph above. VTCs will be used for the real-time exchange of information with selected facilities. Collaborative tools will also be used for the real-time sharing and modification of information and documentation.

- Status reporting: NMCC staff will provide status reports to Service headquarters, national agencies and senior national authorities and also for use in regional cooperative activities and for coalition authorities (if 
appropriate). This will be done using NMCC graphical and textual report generation capabilities and transmitted via voice or data communications, printed format, or formal briefing. News media will be notified to inform the public of on-going plans/actions and support available.

\section{Post-crisis operations}

Post-crisis operations are performed once $\mathrm{MoD}$ support to a specific crisis has ceased. Staffing is reduced eventually to the minimal "watch-keeping" level. Postcrisis operations are conducted concurrently with the pre-crisis operations. The following functions are performed:

- After-action reporting/analysis: The NMCC staff will reduce compiled data and analyze operations conducted to identify lessons learned and support future plans and operations. Using databases and office automation tools they will generate after-action reports and will modify existing plans based on the lessons learned. NMCC staff will coordinate lessons learned and changes to joint planning documents with other organizations and agencies, and other nations (if appropriate) that supported the crisis management effort. This will be done through meetings, VTCs, email exchange, and/or collaborative tools.

- Stand-down: NMCC staff will notify military and national agencies of the cessation of military support. News media will be notified to inform the public of these actions. The NMCC will also coordinate with regional/coalition partners, if appropriate, in the termination of the crisis management support.

The NMCC cannot function alone. It is only one element of a national crisis response capability. The NMCC relies on national information sources and, in turn, provides correlated and processed information to national military and civil organizations and agencies. Furthermore, the NMCC may play an important role in regional crisis management activities. It may be used to support national participation in coalition operations, including NATO operations.

NMCC is not intended to replace existing or planned national crisis management system or command center. Instead, the NMCC is planned to complement and to enhance national crisis management capabilities. As such, the NMCC will be integrated in national $\mathrm{C} 2$ system with other national crisis management systems to the maximum extent practical. This requires establishing interfaces between the NMCC and a number of national and regional organizations and systems. These interfaces are identified generically as:

- National Military Service HQs; 
- National Military Information Systems;

- National Agencies and Systems;

- Public Information Agencies and Systems;

- Regional and Coalition Organizations;

- Deployed NMCC Capability;

- Senior Leadership Communications Capability.

In general, these interface categories are optional and implementation will be an object of national decision.

NMCC is a high priority project for the Bulgarian MoD. It is important part of the overall process of $\mathrm{C} 4$ study recommendation implementation and is also a program element of MoD's Main program 10 "C4ISR systems modernization." ${ }^{9}$ The project will be funded by US Government FMF funds for Bulgaria (2001) and by MoD budget funds. According to approved schedule, NMCC is expected to be operational in the end of 2002.

\section{Notes:}

Roland J. Roland, "Applying modeling and simulations to enhance national and multinational cooperation", Information and Security: An International Journal 3 (1999), 1224.

2 National Military Command Center Concept of Operations (CONOPS), Working Document (18 August 2000).

3 Velizar Shalamanov and Todor Tagarev, Information Aspects of Security (Sofia: Procon, 1996). 
4 See Command, Control, Communications and Computers Study for Bulgaria (Hanscom AFB, MA: Electronic Systems Center/MITRE, 2000).

5 Neil Planzer, "Regional Airspace Initiatives in Eastern Europe," ATC Quarterly 2 (AprilJune 2000): pp. 11-16.

6 National Military Command Center Technical Architecture Description (21 August 2000).

7 National Military Command Center CONOPS.

8 Velizar Shalamanov and Todor Tagarev, "Object Oriented Model to Support Early Warning and Rapid Reaction Planning in International Context." in IFAC Conference on Supplemental Ways for Improving International Stability SWIIS'98 (Bucharest: IFAC, 14-16 May 1998), pp. 47-52.

$9 \quad$ Velizar Shalamanov, ed., Cornerstones of Bulgarian Security and Defence Policy (Sofia: Ministry of Defence, July 2001).

Lieutenant Colonel NIKOLAY PETROV is Head of C4ISR section in the "Armaments Policy Directorate" of the Bulgarian Ministry of Defense. He was promoted to this position after serving as Senior Expert in the "Programs for Development of Armaments, Equipment, and Infrastructure" section of the Defense Planning Directorate in the Ministry of Defense. He was born January $1^{\text {st }}, 1959$ in Montana, Bulgaria. LTC Petrov graduated Technical University in Sofia in 1982. He has a M.Sc. Degree in Computer Automation of Industry. He served as a Chief of section "Automation" in Central Command Post of Bulgarian Air Force until 1990 and as Chief of section "Systems" in Air Force HQ Computer Center until 1998. He graduated USAF BCOT course in Keesler Air Force Base in 1998. 